\title{
A methodology of measuring human health
}

\author{
B.R.K. Sinha* \\ Banaras Hindu University, India
}

Health is an important measure of people's well-being and has always been a major thrust area of geographical inquiry. Several geographers and scholars from other disciplines have made their best attempts at analyzing and mapping health data but have not paid much attention in deriving health index. Devising an index of health of the target population of a region is of great interest to geographers because health (a state of complete physical, mental and social well-being) is an output of society, an asset or wealth for a community, a resource in the form of energy, ability, talents and other mental and physical capabilities of normal functioning in a given environment. Many scholars consider health as a subjective state that has several dimensions. It varies in place and time at age, gender, social class, education, income and occupation levels. Such aspects of the population vary from region to region and work as determining factors of health. This paper aims at highlighting the fundamental steps of methodology and at developing the way of constructing a logical and reasonable composite index to measure health at the individual level in a given area at a given point in time. To accomplish the objectives, several health parameters have been suggested and arranged in a logical and practical form for ranking and assigning an acceptable weight as per the nature of health variables for devising Health Index as a result or as a guiding tool to apply by the health researchers in the field of study of health at individual level.

Key Words: methodology, human health, health indicators, questionnaire.

Article Info: Received: September 10, 2015; Revised: October 24, 2015; Accepted: November 9, 2015; Online: November 30, 2015.

\section{Introduction}

Health, being an important measure of people's well-being, has always been an important thrust area of geographical inquiry. Many geographers, however, have made their best attempts at analyzing and mapping health data but have

\footnotetext{
* Correspondence address

Address: Faculty of Science, Banaras Hindu University, Varanasi 221005, U.P. India.

Phone: 0091-542-2570864 | Email: sinha_brk@yahoo.co.in
} 
not paid much attention in deriving health index. Devising an index of health of the target population of a region is of great interest to geographers because health (a state of complete physical, mental and social well-being) is an output of society, an asset or wealth for a community, a resource in the form of energy, ability, talents and other mental and physical capabilities of normal functioning in a given environment. It helps increase welfare level, quality of life and wellbeing of a person by liberating him/her from several social, cultural, economic, political and environmental constraints.

According to Jane Stein, (1997, p. 78) 'health is an important value not just because it is an end in itself, but because it is also a means to an end - a prerequisite for equal opportunity to participate in the benefits of organized society. The World Bank's Sector Strategy (1997, p. 2) rightly pointed out that good health contributes to the overall quality of life as well as to productivity. From this perspective the health index becomes fundamental especially when the question of what, how, when and where to measure something arises. Here, how to measure the health of the people either at spatial, temporal, household or individual level needs a detailed description of methods. In fact, the methodological approach becomes instrumental in obtaining the result of the concerned objective.

\section{Objective}

Here, the objective is to highlight the fundamental steps of methodology and to develop the way of constructing a logical and reasonable composite index to measure health at the individual level in an area of study at a given point of time.

\section{Methodology}

Methodology deals with the strategy or plan of research or in other words, the way or manner in which research is to be carried out. It is a cornerstone upon which the contents, the quality, dimension and structure of the work largely depend on. It comprises the procedures, techniques, practices, logic, general principles of the formation of knowledge and a set of working methods applied in research. It includes both the database and concept base. According to Patterson John L. (1984, p.9) methodology is an organization of the analysis of the reality, identifying the type of analytical techniques and appropriate instruments to be used. In the words of Kothari, C.R., (1985, pp. 10-11) research methodology is a way to solve the research problem systematically. Research methodology has many dimensions, and research design is one of them. The scope of research methodology is wider.

However, the following order concerning various steps provides us a useful procedural guideline regarding the research process. These are: 1. formulating the research problem; 2. extensive literature survey; 3. development of working hypotheses; 4. preparing the research design; 5. determining sample design; 6.collecting the data; 7. execution of the project; 8.analysis of data; 9. hypothesistesting; 10. generalizations and interpretation; 11 . preparation of the report under study. Essentially two steps are involved in formulating the research problem, viz. understanding the problem thoroughly, and rephrasing the same into meaningful 
terms from an analytical point of view. The best way of understanding the problem is to discuss it with the experts in an academic institution.

The methodological approach can also be termed as the methodological design used in solving a purpose of the inquiry. Here, the methodological approach for identifying human health encompasses specific steps or procedures of research which are clearly explained in the following research design.

\section{Research design}

A research design is the blueprint or framework or overall strategy of the study that a researcher chooses to integrate the different components of the study in a coherent and logical way to ensure to address the research problem effectively. In other words, research design is a detailed outline of an investigation relating to the case under study.

It generally includes all those steps and aspects which start right from identifying or choosing problem, selecting study area, review of literature, defining objectives, formulating procedures of field survey and data collection, synthesis, analysis and interpretation of the facts or data by employing descriptive or statistical tools and techniques to arrive at a set of reliable conclusions or findings.

Susan Carroll at http://www.dissertation-statistics.com/research-designs.html made a list of several research designs that an investigator could use for writing a thesis, report, and dissertation, research paper.

These are Historical Research Design, Case and Field Research Design, Descriptive or Survey Research Design, Correlational or Prospective Research Design, Causal-Comparative or Ex Post Facto Research Design, Developmental or Time Series Research Design, Experimental Research Design, and QuasiExperimental Research Design.

Thus, research design outlines overall procedural or technical steps of research methodology right from selection of research theme, framing objectives, review of related literature, selection of different quantitative and qualitative health indicators, preparation of questionnaire, field survey and data collection, tabulation, process of making ranks and putting certain positive and negative weight on each positive and negative variable respectively, and use of statistical and cartographic technique and tools for interpreting and analysing health of the people of a given area at a given point in time.

\section{Review of related literature}

It is one of the basic steps of a research. The quality of research depends to a large extent on an intensive study of literature related to the theme of one's research. It is the main work of a researcher as he/she gets acquainted with the works already carried out, practiced and knowledge/ideas or methodological concepts developed by others. Before constructing a questionnaire, writing thesis, project report, and paper/article, etc. researcher should consult the works that have already been done by other scholars. Any published or unpublished documents containing information, ideas, facts, concepts, etc. may be book, article, paper, thesis, report, 
monograph, etc. In this sense, literature related to a particular theme always remains secondary in nature.

A literature review aims to have a critical look at the existing research containing current knowledge and or methodological approaches on a particular topic. It precedes a research proposal and results section. It brings the reader up to date with current literature on a subject and forms the basis for another goal, such as future research that may be needed in the area. A well-framed literature review is characterized by a logical flow of ideas, current and relevant references with consistent and appropriate referencing style, proper use of terminology and an unbiased and comprehensive view of the previous research on the topic. In fact, it is a description of the literature appropriate to a particular subject. It gives an overview of what has been said, who are the main writers, what are the prevailing theories and hypotheses, what questions are being asked, and what methods are appropriate and useful. Therefore, a literature review surveys scholarly articles, books and other sources such as dissertations, conference proceedings, etc. relevant to a particular issue, area of research or theory of a researcher. To measure the health of an individual or a group of persons or the people of an area needs an intensive review of the health-related literature to generate a set of health-related ideas or facts applicable and required in formulating further steps towards completion of the work.

\section{Concepts related to health and health parameters}

Since the concept of health is very complex, it needs to understand its different dimensions before selecting the appropriate and relevant parameters of measuring health. Health of population of an area has several dimensions such as quantitative and qualitative, physical and mental, positive and negative; social, cultural, economic, political, environmental, spiritual, emotional, vocational, curative and preventive, etc. and all these are related to health.

'Quantitative' stands for size, magnitudes, dimension, amount, sum, etc. that can be measured directly in number and weight and lead to statistical treatment.

The term 'Qualitative' on the other hand stands for nature, capacity, ability, knowledge, skill, mental or physical attribute, trait, aptitude, attitude, value, motivation and other characteristics of person that can not be measured in terms of number or weight and do not, therefore, lend themselves as easily to statistical treatment as quantitative characteristics.

The quantitative and qualitative features of a person do not work in isolation. One can not be separated from the other. The combination of both becomes a source of better health in human beings and plays an instrumental role in social, cultural, economic and political development. Becker, G. S. (1979, p. 16) also mentioned that a person can not be separated from his/her health. In fact, the relation between the quantitative and qualitative dimensions provides us clear ideas or understanding about the ingredients of health.

'Physical' and 'Mental' are the two essential components of health and play an instrumental role in every kind of physical and intellectual growth of a person. Both involve the quantitative and qualitative growth with reference to physical and mental aspects of the population of an area over a given period of time. Both 
address about how the health ingredients relating to the physical and mental aspects of individuals change or stay the same over time.

The overall performance of health is the combination of both the physical and mental faculty which is found varying during different stages (usually estimated at certain age level) of the life span of an individual. Papalia, Diane E. and Olds Sally W. (1992, pp. 3-8); and Dacey, Jhon S. and Travers, John F. (2004, p. 8) have given a detailed description of the physical and intellectual development of an individual that took place during eight stages of his/her lifespan. These eight stages, according to them, are the prenatal stage (conception to birth), infancy and toddlerhood (birth to age 3 ), early childhood (3 to 6 years), middle childhood (6 to 12 years), adolescence (12 to 20 years), young adulthood (20 to 40 years), middle age (40 to 65 years) and the late adulthood (65 years and above) and affect health status of individuals.

Physical dimension refers to the state of the body, its compositions, development, functions, maintenance, etc. In fact, physical dimension is meant for the growth, improvement, and enhancement and for an increase in the status of physical faculty of an individual.

This dimension stands for sound physical stamina, muscular capacity, sensory capacity, race characteristics, etc. According to Park, J. E., and Park, K. (1991, pp.12-13) physical dimension of health implies the notion of perfect functioning of each and every cell or organs of the body of a person. Suryakantha, A. H. (2009, p. 6) also referred physical dimension to physical health and mentioned that a person is said to be physically healthy when all the organs and systems in the body function perfectly at their optimum capacity.

Mental dimension refers to the right, fit and healthy creative abilities of the mind. This dimension also stands for a state of balance between the individuals and the surrounding world, a state of harmony between oneself and others, coexistence between the realities of the self and that of the other people and that of the environment (Park, J.E., and Park, K. 1991. P. 13). In fact, this dimension is an essential component of health and meant for enhancing, upgrading, improving and increasing the status of mental or intellectual capability such as learning, memory, reasoning, thinking, competence and other intellectual capacities of an individual. More or less the same factors as stated in the context of physical dimension are equally important for mental health also. Here, it can be stated that all the elements of physical and mental health can be considered as vital indicators of human health.

'Positive' and 'Negative' dimensions refer to the positive and negative functions of different organs or systems of the body and mind of the concerned persons. These are very significant characteristics of the health of the population. Here, positive dimension stands for positive growth and positive function of different organs or systems of the body and mind. Such positive function or growth boosts up the well-being of the people. Contrary to this, negative elements or aspects stand for loss, deterioration, depreciation caused by disease or other factors in both the physical and mental health status of the people of a region at a given point in time. Dreze, Jean, and Sen, Amartya (1999, pp. 10-13) rightly said that human capability can be seen as the central feature of the process of development, and human capability can be enhanced by economic growth, education, and health (social variables). 
According to Park and park (1991, p.14) the state of the positive health (functional ability or capacity to work) implies as the notion of perfect functioning of the body and mind. It is also a reality that positive health always remains a mirage because everything in our life is subject to change in the surrounding environment and that is why nobody is considered perfectly healthy. It is because of the fact that somehow or other everyone stands with some sort of deviation from the normal function of health, and that is how the range of positive and negative dimensions of health varies from person to person.

Positive development of health depends on congenial environment, well educational system, income, food and nutrition, proper food and drinking habits, proper lifestyle, health care, self care, health delivery, capital investment, proper housing condition, absence of illness or disease and other physical, social, economic, cultural and political factors operating positively in the society of a region. Similarly, negative dimension is the result of diseases or illness, poverty, illiteracy, bad habits or bad lifestyle of a person in taking food, drink, smoking; lack of proper and adequate food and nutrition, lack of medical and educational facilities, lack of curative and preventive systems, environmental pollution and other natural, social, cultural, economic and political situations operating negatively in the society of a region.

'Social Dimension' focuses on the social environment in which the people live and perceive health. A person is said to be socially healthy, when he is accepted, respected and loved by all in the family, by his friends, relatives, neighbours, colleagues, and others. Social well-being implies harmony and integration within the individual, between each individual and another member of society and between individuals and the world in which they live. It has been defined as the "quantity and quality of an individual's interpersonal ties and the extent of involvement with the community". In the words of Suryaknatha, A.H. (2009, p. 6) the social dimension of health includes the levels of social skills one possesses, social functioning and the ability to see oneself as a member of a larger society. In general, social health takes into account that every individual is part of an economic conditions and well-being of the "whole person "in the context of his social network. Social health is rooted in "positive material environment" (focusing on financial and residential matters), and "positive human environment "which is concerned with the social network of another individual.

'Cultural Dimension' relates all those components that are linked to various cultural elements and among all education is very vital in influencing the health of an individual. In fact, literacy and education are the powerful means of human health. They are viewed as a strategic tool and play a vital role in achieving and maintaining health. Education and learning are in one form or another helping to enhance health, increase knowledge and skills of the persons of various ages, sex, religion, social groups and occupation. Suryaknatha, A.H. (2009, p. 9) has observed that illiteracy is associated with increased morbidity and mortality, especially female literacy level is crucial. Harbison and Myers (1964, pp.2-3) rightly emphasized the role of education in human resource (health) development. According to him "education plays a dominant role as an effective instrument for considerable achievement and revolution in all spheres.

Purposeful education enables the individual to understand and study the real life situation and to develop an opportunity for creating confidence in the minds of 
a younger generation and provide a strong base for national and value oriented and nation-building progress.

Rena, R (2006, p. 67) noted that technical and vocational courses in higher education play a significant role in developing human resources or health resources. Education is, in fact, considered as an instrument for enhancing knowledge, skills, health status and other functional capabilities in human beings. Education from primary to secondary and higher levels of education makes a variation in the status of health. These categories vary across race, gender, age and social and economic class and become an effective tool for analyzing the dimensions of the health of the people of an area.

'Economic Dimension' includes all those elements that are related to the economy such as income, occupation, employment, working culture, etc. They are essential since they can affect much the health of someone. In this sense, professions and health are some of the relevant fields in medical geography. Working populations are found actively engaged in various occupations in both the rural and the urban areas. The level or status of health is generally found associated with income, employment, and professions of the person. For instance, the level of health in terms of qualitative achievement is usually low in the agricultural sector, and it is generally high in the non-agricultural sector.

According to Suryaknatha, A.H. (2009, p. 9) occupation is one of the elements of the economic dimension. Morbidity and mortality are more among the unemployed persons than among the employed persons. Unemployment causes psychological and social damage, and many occupations affect health. Similarly, income determines the standard of living, quality of life and health status of the individual and community at large.

Diseases of the poor socio-economic status are malnutrition, tuberculosis, leprosy, gastroenteritis, worm infections, etc., and the diseases of the affluent society are obesity, hypertension, coronary artery disease diabetes, etc. Certain occupation often plays a role in promoting both the physical and mental health. Physical work is usually associated with and improvement in physical capacity, while goal achievement and self-realization in work are a source of satisfaction and enhanced self-esteem.

'Political' dimension includes health policy elements as health indicators, and these may be a political commitment to health for everyone, equitable resource allocation and distribution, the degree of equity of distribution of health services, community development, organized framework and managerial process as well as right official policy and decision. These considerably contribute to community health.

'Environmental' aspects shed light on the indoor and outdoor environment. Indoor environment refers to the environment of a built-up space where or in which a person or persons or people spend most of their time. This may include lighting, ventilation, dampness, air quality, surface contamination with toxins and microbes, and contact among persons or people at home, work place, public and private built places. Outdoor environment refers to the condition of air, water, dust, noise, temperature, rainfall, soil, greenery, plants and animals, culture, beliefs, traditions, customs, etc. that prevails outside the built-up places. All these directly or indirectly, favourably or unfavourably affect health of an individual(s) or people of an area. 
'Spiritual' dimension is nowadays is considered to be important in the field of human health. A person is said to be spiritually healthy when she/he possesses, sound mind in a sound body and simple living and high thinking in day to day life. '

Emotional' dimension also plays a role in the health of an individual. An individual is said to be emotionally healthy when he does not loose temper or does not develop tension and has self- control. The mental and emotional dimensions have been seen as one element or as two closely related elements.

'Vocational' dimension refers to the vocational aspect of life. It is part of human existence. When work is fully adapted to human goals, capacities, and limitations, work often plays a role in promoting both physical and mental health. Physical work is usually associated with and improvement in physical capacity, while goal achievement and self-realization in work are a source of satisfaction and enhanced self-esteem. The importance of this dimension is exposed when individuals suddenly lose their jobs or faced with mandatory retirement. For many individuals, the vocational aspect may be merely a source of income. To others, this dimension represents the culmination of the efforts of other dimensions as they function together to produce what the individual considers success in life.

'Curative and Preventive' measures are also important in determining the health of individuals of an area at a given point in time.

\section{Selection of health indicators/variables}

From the above it is quite clear that health entails a variety of elements relating to various dimensions of health but all these elements are focused on and centered on the physical and mental aspects of an individual. Several health experts believe that there is no reliable statistical indicator of measuring human health, and the construction of an index of health remains tough. No one has yet developed a comprehensive set of variables or indicators for assessing the health of persons of a region because health involves a number of quantitative and qualitative variables from several health dimensions. Selection of variables plays a significant role in a proposed field-based research.

According to Ahuja, R. (2003, pp. 64-65) the quantitative variable is one whose values or categories consists of numbers and differences between its categories can be expressed numerically. Thus, age, income, size, etc. are quantitative variables. The qualitative variable is one which consists of discrete categories rather than numerical units. This variable has two or more categories that are distinguished from each other. Class (lower, middle, upper), caste (low, intermediate, high), sex (male, female), religion (Hindu, non-Hindu), are all qualitative variables. Both the quantitative and qualitative variables have positive and negative nature in the context of its use and, as a result, health becomes positive and negative.

Raza Moonish (1990 p. 47), Trewartha, G. T. (1967 p. 546), Smith, D. M. (1997, p. 47), Basu, S. (1992, pp. 212 - 226), Pacione, M. (1988, pp. 211 - 212), Madan, G. R (1983, p. 284, 286), Mukherjee, B. M. (1986, p. 102), African Development Report on Human Capital Development (1998, p. I), Singh, A. K. (1983, pp. 27 - 31), Human Development Report (1998, p. 46) and others have used different quantitative and qualitative indicators such as height and weight of the body, body temperature, blood pressure, counts of red blood and white blood corpuscle, infant 
mortality rate, general mortality, problems of hair, eyes, lips, gums, teeth, skin, gland, life expectancy, mortality, morbidity, number of doctors, hospital and beds per unit population, safe water supply, literacy, education, per capita income, expenditure on health, disease of various types, food and nutrition, calorie intake, capacity to do manual work for standard working hours, clear eyesight and memory condition etc. in measuring health of the people but most of their quantitative and qualitative indicators are applicable to the common people at regional, state and national levels only.

\section{Indicators applicable at the individual level}

Indicators to be used for measuring health at the individual level are directly or indirectly related to mental and physical aspects of an individual. These are the number and types of diseases, condition of appetite, digestive problem, memory capacity, mental tension, blood pressure, eye problem, E.N.T problems, dizziness, physical and mental problem while working continuously for 6 - 8 standard working hours, problems arise during working period in the sun, rain and cold, problems in carrying normal head load (for working persons), state of sleep, feeling of weakness and tiredness, feeling of laziness, whether breath is sweet or not, whether enthusiastic to work, whether two time meals and breakfasts are taken in time, number of visit to government and private hospitals or clinics, per head total medical cost in the last one year, types of drinking water, number of days of pulse, green and other vegetables taken by the individual in a week, how many days in a week an individual takes ghee/butter, milk, eggs, meat, fish; frequency of smoking, consuming tobacco, alcoholic materials; whether the required medicines are purchased timely or not and whether the food is adequately available or not at household level, whether the house is ventilated or unventilated, women married between age 12 and 18, birth spacing of children, women worked during and after delivery period, persons worked during adverse circumstances, economic participation of children below 15 years, health-related amenities, educational achievements including training and skills and income levels. Such other relevant indicators relating to health can also be incorporated. Some of these elements help improve, maintain good health of the concerned persons by interacting and influencing positively while some others deteriorate and weaken health by its negative interaction or negative influence in many ways.

\section{Preparation of questionnaire}

Questionnaire is the structured set of questions. It is also known as a document or schedule. It is one of the important tools of research. It is also considered as a means or schedule of obtaining information. In a broader sense, it is a list of written or printed questions relevant to the proposed research and to be answered by a respondent. This helps an investigator in collecting the detailed facts or information from a defined geographical unit during the field survey. Therefore, the questionnaire should be constructed in a systematic manner by obtaining good knowledge and ideas through an intensive review of the literature and incorporating health-related relevant quantitative and qualitative variables as suggested above. 


\section{Field survey and health data collection}

Field Survey and health data collection are very important for a field-based research. Data may be primary and secondary. Both are useful, but its use depends on the nature of the objectives of the proposed work to be carried out. Primary data are very vital. Ghosh, B.N. (1987, pp. 14-15) stated that data may be collected from a particular family, household or individual. Such data will be of micro-level data which are used for the micro level study. Data may also be collected from various families for the system as a whole for macro level study. The macro level study requires macro level data which are to be collected for the country as a whole for finding some useful conclusions which will have policy implications.

Data may be personally collected by the researcher / investigator through questionnaires, schedule or personal interview methods and the data collected at the individual level from the selected sampling unit(s) will become primary source data. Statistical data may also be collected from published sources such as books, reports, journals, thesis, and other published documents as supplementary data of secondary source. Such procedure of data collection is known as the Secondary Method of data collection.

For measuring individual's health collection of primary data is preferred. It involves sampling procedures also. Sampling is the process of selecting units (e.g., people, spatial units, organizations) from a population of interest so that by studying the sample we may fairly generalize our results back to the population from which they were chosen. A sample is a proportion of persons drawn from a larger population. It is representative of the universe population of an area. Selection of geographical units for sample survey is another important step of methodological procedures. Sample survey is a major source of obtaining comprehensive and continuing information from the field. It is generally meant for a particular study or special purpose.

According to Ghosh, B.N. (1985, p. 18) a special purpose survey is that in which data obtained are useful in analyzing a particular problem of research. There are several types of sampling such as simple random sampling, stratified random sampling, systematic sampling, cluster sampling, purposive sampling, etc., and a researcher has to choose a particular type of sampling that most suitably fit to the defined objectives of the proposed research. Therefore, depending on the nature of the work, requirements of the types and volume of data, selection of sample spatial units becomes imperative.

For measuring individual's health the selection of family household both in the case of rural or urban areas becomes necessary. While selecting households at least ten percent households from the total households of a chosen spatial unit comprising different groups/classes of socio-economic background should be chosen. The households for individual health data collection should be selected either by the random method or by another appropriate sampling method.

\section{Preparation of master data sheet}

This is another important step of data related procedures. After the work of data collection of primary and secondary types through questionnaire from the 
household survey and from the secondary sources respectively is over, the process of transferring data from questionnaires to master data sheets (either manually or in computer) should be done and each health variable should be assigned certain positive or negative weight depending on its positive or negative nature for further calculation of composite scores for preparing relevant tables.

\section{Tabulation work and use of statistics}

After the work of preparation of master data sheets is done, relevant tables to satisfy the defined objective should be carefully prepared. While preparing, tables suitable statistical techniques should be employed.

\section{Data base cartographic work}

This, being another important step of methodology helps in giving the final shape of tables, maps, diagrams, etc. Cartographic representations in the form of maps, diagram, charts, etc. become the important tools and easily help in explaining and interpreting the facts and in bringing the results of the work under investigation. The same is to be followed in case of measuring human health.

\section{Rank and weight of the health indicators}

After completion of household sample survey, the following health indicators should be assigned certain positive or negative weight (as stated above in the preparation of master data sheet) depending on its positive or negative nature. The

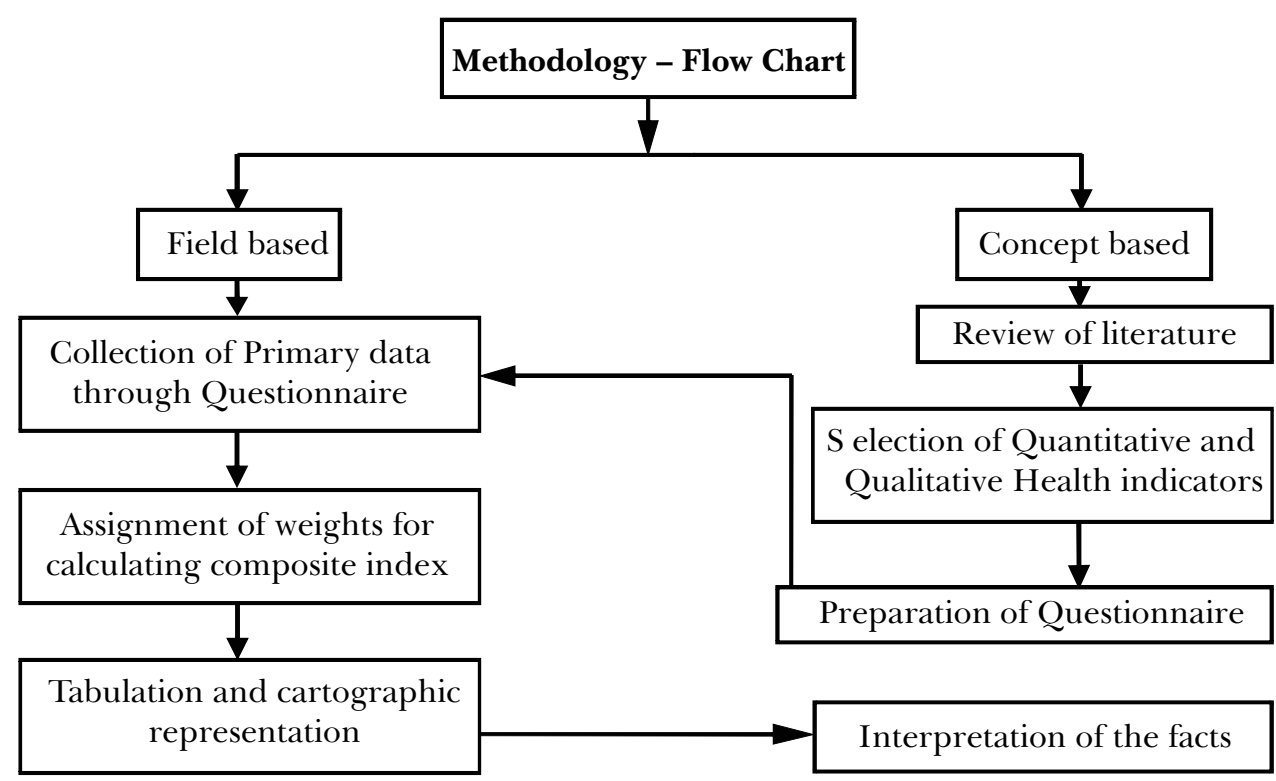


weight value is arbitrary, however, while assigning weight it should be kept in mind that the value of weight remains equal and common for each person. This will help in making the result free from any kind of biases.

\section{Health criteria, rank, and weightage}

\section{(I) Educational Attainment in terms of completed length of schooling of individual}

Since education is a positive element of health, it carries only positive weight. In order of relative importance educational attainment of a person can conveniently be grouped and assigned weight as under Illiteracy: 1; standard I - VIII: 2; standard VIII - XII: 3; B.A./B.Sc./B.Com. \& M.A./M.Sc./M.Com: 4; and Professional/technical: 5 .

\section{(ii) Monthly Income of Earning Members (in Rs.) and Weightage}

Income again is a positive component of health, and that is why the monthly income of individual can practically be divided into the following groups and accordingly weighted in order of its relative value. <1000: 1; $1001-5000: 2 ; 5001$ - 10000: 3; 10001 - 20000: 4; and >20000: 5 .

Income group and its relative positive weight depend on the nature of variation in the monthly income of all individuals under study.

(iii) Weightage of the Quantity of Green Vegetables, Eggs, Fish, Meat, Milk, Fruits Consumed by Individual in a Month

Green vegetables, eggs, fish, meat, milk, fruits consumed by individual in a month work as positive components of health because these are the items of food and nutrition required by an individual. On the basis of the quantity of green vegetables consumed per month, the following categories can purposefully be made, and good weight can accordingly be assigned. These may be $<3 \mathrm{~kg}-1 ; 3 \mathrm{~kg}-2$; and $>3 \mathrm{~kg}-3$. Similarly, consumption of eggs, milk and fruit depends on the basis of information gathered from individuals during the field survey regarding consumption of such items in Yes or No. If the information is in Yes, then the weight to be assigned may be or should be +1 , and in the case of $N o,-1$. Individual's response regarding consumption of fish and meat may be sought in terms of 'never', 'occasionally' and regularly and can be weighted in the value of $-1,+1$ and 2 respectively.

\section{(iv) Amenities and Weightage}

Social amenities or facilities play a positive role in enhancing and maintaining health. Responses regarding the availability of medicines and availability of resources for purchasing, availability of medical and health care facilities, availability of transport facilities and its accessibility to health centers may be asked in Yes or No and weight can accordingly be assigned in +1 or -1 .

\section{(v) Physical Conditions and Life Style and Weightage}

These also play a vital role in the health of an individual. Physical conditions include blood pressure, appetite condition, digestive and memory condition as indicators of health. Lifestyle includes smoking, alcohol drinking, chewing 
tobacco, doing physical exercise, use of medicines, food and breakfast taken in time or not and such other lifestyle related elements. Blood pressure may be grouped into high, normal and low and if this is not well controlled then it creates several health problems. The information with regard to high, normal and low blood pressure can be sought from the individuals during the field survey and can be weighted by $-2,+2$ and -2 score respectively.

Similarly, appetite, digestive and memory condition can purposefully be grouped into Good, Normal and Not Good. The investigator can gather information regarding these conditions from individuals in the field and give the weight of $+2,+1$ and -2 respectively. Smoking, alcohol drinking, chewing tobacco, doing physical exercise, use of medicines, food and breakfast taken in time or not are very much related to individual's health condition and sometimes create health problems.

Physical exercise practiced may be grouped into Regularly, Occasionally and No category and can be assigned a score of $+2,+1$ and -2 respectively. However, this criteria may especially be applied to the persons of middle and upper age. Similarly, medicines taken by individuals may also be grouped into Regularly, Occasionally, and No category and can be assigned a score of $-2,-1$ and +2 . The investigator can gather information regarding the use of alcohol, smoking, chewing tobacco, untimely eating food and breakfast in the form of Yes or No and give the weight of +2 and -2 respectively.

\section{(vi) Medical Cost (in Rs.) incurred on Individual in the last one Year and Weightage}

Medical cost is also related to the status of individual's health. Generally, a higher cost of treatment of diseases or ailments indicates to a health problem. Medical cost may conveniently be categorized as <200, 201-600, 601-1000 and $>1000$ or so on as per the field information and can be assigned a weight of $-1,-2,-3,-4$, or so on.

\section{(vii) Housing condition and Weight}

Physical condition of housing is an important part of human health. There are a number of aspects of housing that are understood to have a direct impact on health. The information regarding the existence of garden space, separate kitchen, courtyard; availability of sufficient beds, dining space; well ventilated house, congested house; paucity of housing space, regular maintenance of house, damped house, exposure of adequate sunlight in the house, link of water outlet drain, well maintained drain, drain overflowing, chemical use in drain, and cleanliness, etc. can be sought from the respondents (applied in whole family members) during the field survey in terms of Yes or No answer and weighted value in case of Yes can be +2 and, in case of $N o-2$ respectively.

\section{(viii) Environmental Items and Weightage}

Environmental conditions or surroundings in which the persons live and experience effect on health because environmental items have a great role in health of the people. The common environmental items may be: link of the toilet to sewerage; disposal of garbage: near the house, away from the house, in public dustbin; separate cowshed; use of mosquitoes net; clean street; friendly, quiet and cooperative neighbourhood, etc. The investigator can collect information about 
these items in Yes or No during the field survey and depending on answer Yes, the weighted value should be +1 and depending on answer $N o$, the weighted value should -1 .

(ix) Health Indicators and Weightage (Positive E Negative); and (x) Disease Recording Negative Weightage (in descending order)

The following Chart (ix) includes those mental and physical health-related elements which have profound effects on the health of an individual. The researcher can gather information relating to these items from a field survey in terms of Yes or $\mathbf{N o}$ and can conveniently assign a weight of $\mathbf{- 2}$ or $\mathbf{+ 2}$ depending on Yes or No response furnished by the respondent about self as well as family members. Chart (x) shows only diseases which have solely negative effects on the health of an individual and have been arranged on the basis of severity in descending order as suggested by medical practitioners and literature relating to a world ranking of diseases and mortality and ranked and weighted accordingly. However, there are many other diseases that occur in different parts of the world. The active researcher has to get information regarding diseases existing in the area under study and can re-arrange, regroup and re-weight. This chart is just as an example, based on author's field survey experience, to guide, help and follow.

(ix) Health Indicators and Weightage (Positive \& Negative)

\begin{tabular}{|l|c|c|}
\hline \multirow{2}{*}{ Health Indicators } & \multicolumn{2}{|c|}{ Weight } \\
\cline { 2 - 3 } & Yes & No \\
\hline Mental Tension & -2 & +2 \\
\hline Dizziness & -2 & +2 \\
\hline $\begin{array}{l}\text { Physical/mental problem } \\
\text { during normal working } \\
\text { hours }\end{array}$ & -2 & +2 \\
\hline $\begin{array}{l}\text { Problem during rain, sun, } \\
\text { cold while working }\end{array}$ & -2 & +2 \\
\hline Tiredness & -2 & +2 \\
\hline Laziness & -2 & +2 \\
\hline $\begin{array}{l}\text { Physical/Mental problem } \\
\text { in carrying normal head } \\
\text { load }\end{array}$ & -2 & +2 \\
\hline Enthusiastic to work & +2 & -2 \\
\hline Timely meal taken & +2 & -2 \\
\hline ENT problem & -2 & +2 \\
\hline Tooth / Gum problem & -2 & +2 \\
\hline Breathing trouble & -2 & +2 \\
\hline Shining complexion & +2 & -2 \\
\hline Eye problem & -2 & +2 \\
\hline Hair problem & -2 & +2 \\
\hline $\begin{array}{l}\text { Smoking/chewing } \\
\text { tobacco }\end{array}$ & -2 & +2 \\
\hline $\begin{array}{l}\text { Consumption of } \\
\text { Alcoholic materials }\end{array}$ & -2 & +2 \\
\hline Sound sleep & +2 & -2 \\
\hline
\end{tabular}

(x) Disease Recording Negative

\begin{tabular}{|l|c|}
\hline Disease & $\begin{array}{l}\text { Negative } \\
\text { Weights }\end{array}$ \\
\hline Stroke/ Heart disease & 20 \\
\hline Cancer / Tumor & 19 \\
\hline Paralysis & 18 \\
\hline Diabetes & 17 \\
\hline $\begin{array}{l}\text { Liver problem / Jaundice / } \\
\text { Ulcer }\end{array}$ & 16 \\
\hline Tuberculosis & 15 \\
\hline Kidney & 14 \\
\hline Malaria & 13 \\
\hline Gastric / Acidity & 12 \\
\hline $\begin{array}{l}\text { Asthma, Cold-cough and chest } \\
\text { pain }\end{array}$ & 11 \\
\hline Epilepsy / Hysteria & 10 \\
\hline Gynecological disease & 9 \\
\hline Fever / Typhoid / Pox & 8 \\
\hline Anemia & 7 \\
\hline G.B. Stone / Hernia / Hydrocil & 6 \\
\hline Polio & 5 \\
\hline Arthritis and Spondylitis & 4 \\
\hline Skin disease / Leprosy & 3 \\
\hline $\begin{array}{l}\text { Amebiosis /ascariasis Stomach } \\
\text { problem }\end{array}$ & 2 \\
\hline Others & 1 \\
\hline
\end{tabular}




\section{Computation of Composite Scores and Health Index}

Composite Scores

After putting assigned weight against each positive or negative variable, the total composite scores (an outcome of positive + negative scores) of all variables for each person should be found out.

Thereafter, the percentage of total positive or total negative scores for each person should be worked out. While doing so, the total composite scores (value of total positive and negative scores) should be considered as $100 \%$. Later, Health Index for the Positive and Negative performance of each person should be separately calculated dividing the percentage of total positive or negative scores of each person by 100 .

Finally, on the basis of variation in Health Index of the Positive and Negative performance among the persons under investigation a conveniently sequential arrangement of this in certain groups or levels at equal class interval should be framed for tabulation, cartographic representation, and interpretation.

\section{Result}

Meaningful Framework of Positive and Negative Health Index and Level

The following arrangement, for example, can be made to provide a meaningful and acceptable framework for measuring and interpreting health status of the surveyed people of an area at a given point in time.

Health Index and Level

(i) $>0.80$ (Very Good), (ii) $0.61-0.80$ (Good),

(iii) 0.41-0.60 (Average), (iv) 0.21-0.40 (Poor), and

(v) $<0.21$ (Very Poor).

These are in terms of Positive Dimension of Health.

Similarly, in terms of Negative Dimension of health, the level or status and index can be framed as:

(i) $>0.80$ (Very High Negative), (ii) 0.61-0.80 (High Negative),

(iii) 0.41-0.60 (Average Negative), (iv) 0.21-0.40 (Low Negative) and

(v) $<0.21$ (Very Low Negative).

Thus, the above approaches appear to be more realistic and proper in order to make an assessment of the dimensions of the health of the surveyed people of the area under study.

Use: such sequential arrangement of Health Index can be used for explaining health status of individuals by age and gender; social class/group; race, ethnicity, religion, educational level, income level and by occupational categories in the rural or urban area. 


\section{References}

African Development Report 1998, on Human Capital Development, African Development Bank, Oxford University Press, New York.

Ahuja, R 2003, Research Methods, Rawat Publications, Jaipur, India.

Basu, S 1992, 'Nutritional status, Physical growth, Trends and Health problems among the tribal population of Bastar district, M.P.', in PD Tewari \& RS Tripathi, Dimensions of Scheduled Tribes Development in India, Uppal Publishing House, New Delhi.

Becker, GS 1979, Human Capital: A Theoretical and Empirical Analysis with special references to Education, University of Chicago Press, USA.

Dacey, JS \& Travers, JF 2004, Human Development across the Lifespan, Mc Graw Hill companies, Inc., New York.

Dreze, J \& Sen, A 1999, India: Economic Development and Social Opportunity, Oxford University Press, New Delhi.

Ghosh, BN 1987, Fundamentals of Population Geography, Sterling Publishers Private Limited, New Delhi.

Harbison and Myers 1964, Education, Manpower and Economic Growth: Strategies of Human Resource Development, McGraw Hill Book Company, New York.

Human Development Report 1998, United Nations Development Programme (UNDP), Oxford University Press, Delhi.

Kothari, CR 1985, Research Methodology - Methods and Techniques, weshw prakashan, New Delhi.

Madan, GR 1983, India's Social Problems, Social Disorganisation and Reconstruction, vol. I, Allied Publishers Pvt, New Delhi.

Mukherjee, BM 1986, 'Ageing Members and their Health in Changing Techno-Economic Condition' in B Chaudhury (ed) Tribal Health - Socio - Cultural Dimensions, InterIndia Publication, New Delhi.

Pacione, M 1988, The Geography of the Third World: Progress and Prospects, Routledge, London.

Papalia, DE \& Olds, SW 1992, Human Development, Tata McGraw-Hill Publishing Company Limited, New Delhi.

Park, JE \& Park, K 1991, Text Book of Preventive and Social medicine, Banarsidas Bhanot Publishers, Jabbalpur.

Paterson, JL 1984, David Harvey's geography, Groom Helm, London.

Raza, M 1990, Education, Development, and Society, Vikas Publishing House Pvt. Ltd., New Delhi.

Rena, R 2006, Education and Human Resource Development in Post Independent Aritrea: An Explanatory Note, International Journal of Education and Development, Using information and communication Technology (IJEDICT), Vol-II, Issue: 4.

Singh, AK 1983, 'Health Modernity Education in India', Social Change, vol. 13, no. 2, Journal of the Council for Social Development, 53 Lodi Estate, New Delhi.

Smith, DM 1977, Human Geography: A Welfare Approach, Edward Arnold Ltd., London.

Stein, J 1997, Empowerment and Women's Health: Theory, Methods, and Practice, Zed Books, London and New Jersey.

Suryakantha, AH 2009, Community Medicine with Recent Advances, Jaypee Brothers Medical Publishers (P), Ltd. New Delhi.

The World Banks's Sector Strategy 1997, Health, Nutrition \& Population, Human Development Network, The World Bank's Group, Washinton, D.C., USA.

Trewartha, GT, Robinson, AH \& Hammand, EH 1967, Elements of Geography: Physical and Cultural, Mc. Graw Hills Book Company, New York. 